\title{
Attenuation of the Ventilatory and Heart Rate Responses to Hypoxia and Hypercapnia with Aging in Normal Men
}

\author{
Richard S. Kronenberg and Charles W. Drage \\ From the Department of Medicine, University of Minnesota Hospitals, \\ Minneapolis, Minnesota 55455
}

A B S T R A C T The response of ventilation and of heart rate to hypoxia and hypercapnia was determined in eight young normal men age 22-30 yr and eight elderly men age 64-73. The elderly men were selected and carefully screened to eliminate the possibility of cardiopulmonary disease. All the subjects were born at low altitude and had no significant prior exposure to hypoxia. The ventilatory response to hypoxia was measured as the exponential slope constant, $k$, of regression lines relating the logarithm of incremental ventilation to $\mathrm{PAO}_{2}$ during isocapnic progressive hypoxia. The heart rate response to hypoxia was measured as the percentage change in heart rate between $\mathrm{PAo}_{2}=100$ and $\mathrm{PAo}_{2}=40$ $\mathrm{mm} \mathrm{Hg}$. The ventilatory response to hypercapnia was measured as the slope of regression lines relating ventilation to $\mathrm{PAco}_{2}$ during rebreathing with $\mathrm{PAO}_{2}>200$ $\mathrm{mm} \mathrm{Hg}$. The heart rate response to hypercapnia was measured as the percentage change in heart rate between control values at the start of the rebreathing test and $\mathrm{PACO}_{2}=55 \mathrm{~mm} \mathrm{Hg}$.

The ventilatory and heart rate responses to both hypoxia and hypercapnia were significantly decreased in the elderly men as compared to the young men. Hypoxic ventilatory drive was decreased by $51 \pm 6 \%$ (mean \pm SEM $; P<0.001)$ and hypercapnic drive by $41 \pm 7 \%$ $(P<0.025)$. The percentage change in heart rate produced by hypoxia was $34 \pm 5 \%$ (mean $\pm \mathrm{SEM}$ ) in the young normals and $12 \pm 2 \%$ in the old normals $(P<$ $0.005)$. Similar figures for heart rate in response to hypercapnia were $15 \pm 3 \%$ and $-1 \pm 1 \%$ for the young and old normal groups $(P<0.001)$.

We conclude that ventilatory and heart rate responses to hypoxia and hypercapnia diminish with age. These alterations in both ventilatory and circulatory controls could make older individuals more vulnerable to hypoxic disease states.

This paper was presented in part at the Central Society for Clinical Research Meeting, November 1972, Chicago, Ill.

Received for publication 29 September 1972 and in revised form 3 April 1973.

1812

\section{INTRODUCTION}

Within a group of normal subjects, there may be considerable variation in the ventilatory response to hypoxia and hypercapnia $(1,2)$. The reasons for this variation are unclear, but two important factors that appear to reduce the ventilatory response to hypercapnia and greatly diminish or abolish the response to hypoxia, are prolonged exposure to hypoxia (3) and athletic physical conditioning (4). This report will present evidence that a third factor, increasing age, can also attenuate hypoxic and hypercapnic ventilatory drive.

\section{METHODS}

Subjects. The old normal subjects were selected volunteers from a larger group of elderly normal men participating in a long term epidemiological study on heart disease (5). In connection with this epidemiological study, they have been followed with periodic history questionnaires, physical examinations, chest $\mathrm{X}$ rays, electrocardiograms, and the pulmonary function tests listed in Table I. None of the old normal subjects had ever smoked cigarettes. Criteria for subject selection were no evidence for heart disease or cerebrovascular disease and birth at or near sea level with no previous sojourns at high altitude for over 2 mo in any $1 \mathrm{yr}$. Thus the old normal men in this study constitute a select subject group free of significant heart, lung, and vascular disease and with no significant prior exposure to hypoxia.

The young normal control subjects were male college students who had no previous experience with respiratory studies, who had not spent over 2 mo at high altitude, and who were not using drugs. Hypoxic ventilatory response data on the control subjects has been previously reported (6).

Hypoxic response. A detailed description of the method used in these studies has been reported elsewhere (6). The subject breathed through a respiratory valve (Lloyd) into a circle with a variable $\mathrm{CO}_{2}$ absorber bypass rebreathing system. $\mathrm{CO}_{2}$ was continuously sampled by an infrared $\mathrm{CO}_{2}$ analyzer (Beckman LB-1; Beckman Instruments, Inc., Fullerton, Calif.). End-tidal $\mathrm{O}_{2}$ was automatically sampled from beyond the expiratory valve using the method described by Severinghaus and Hamilton (10). Differences between alveolar. $\mathrm{PO}_{2}$ obtained by this method and arterial $\mathrm{Po}_{2}$ were less than $4 \mathrm{~mm} \mathrm{Hg}$ when $\mathrm{PAO}_{\mathrm{O}_{2}}=40 \mathrm{~mm} \mathrm{Hg}$ in the young 
normal subjects. Arterial blood samples were not obtained from the old normal men. Various gas mixtures $\left(\mathrm{N}_{2}, \mathrm{O}_{2}\right.$, $\mathrm{CO}_{2}$ ) were added via flow meters to ports in the circuit for control of desired gas tensions. A suction flow meter permitted this addition of gases without changing the volume of the system. Heart rate was recorded from ECG electrodes applied to the chest. Ventilation was transduced by a potentiometer coupled to a 13.51 spirometer (Warren E. Collins, Inc., Braintree, Mass.) within the circle rebreathing system. All variables were recorded on a polygraph recorder (Grass Model 7, Grass Instrument Co., Quincy, Mass., or a Gilson MSP, Gilson Medical Electronics, Inc., Middleton, Wisc.). Alveolar $\mathrm{Po}_{2}$ was held at $120 \mathrm{~mm} \mathrm{Hg}$ for $2 \mathrm{~min}$ before beginning the hypoxic response tests in order to determine each subject's resting $\mathrm{P} A_{\mathrm{CO}_{2}}$. $\mathrm{PAO}_{2}$ was then lowered from 120 to $40 \mathrm{~mm} \mathrm{Hg}$ over a period of 4-5 min. The induction of hypoxia in this study was somewhat more rapid than that employed by other investigators (11). We have found that there is no difference in results obtained by this method and slower ones (6). Byrne-Quinn, Sodal, and Weil, using the same isocapnic progressive hypoxia technique but a different method of data analysis, also found no difference in results when lowering $\mathrm{PAO}_{2}$ over $5 \mathrm{~min}$ as compared with $15 \mathrm{~min}$ (12). With practice, the variable $\mathrm{CO}_{2}$ absorber bypass could be adjusted to hold $\mathrm{PAco}_{2}$ within $1 \mathrm{~mm} \mathrm{Hg}$ of the previously determined resting level. It was occasionally necessary to add $\mathrm{CO}_{2}$ to the circuit to achieve this degree of $\mathrm{PAco}_{2}$ control. Two isocapnic hypoxic response tests were done in each subject with an intervening rest period.

Ventilation in the hypoxic response tests was measured by averaging inspiratory volume over a minimum of five breaths at approximately each $10 \mathrm{~mm} \mathrm{Hg}$ fall in $\mathrm{PAO}_{2}$. The relationship of ventilation to $\mathrm{Po}_{2}$ at a constant $\mathrm{PCO}_{2}$ has been described as hyperbolic (11). Previously reported work using this technique, however, demonstrated that the logarithm of incremental ventilation is approximately a linear function of $\mathrm{PO}_{2}(6)$. Incremental ventilation is determined by subtracting from all ventilation measurements their non-hypoxic component. The figure used to represent this non-hypoxic component was $85 \%$ of the ventilation at $\mathrm{PA}_{2}$ $=100 \mathrm{~mm} \mathrm{Hg}$. This constant is based on calculations made by Severinghaus, Bainton, and Carcelen in high altitude natives showing that about $15 \%$ of the resting ventilatory drive at $\mathrm{Po}_{2}=100 \mathrm{~mm} \mathrm{Hg}$ is provided by the peripheral chemoreceptors (13). This figure was confirmed by Wade, Larson, Hickey, Ehrenfeld, and Severinghaus in a study of patients with denervated peripheral chemoreceptors (14). Using this method of analysis, the relationship between ventilation and $\mathrm{PO}_{2}$ at constant $\mathrm{PCO}_{2}$ can be expressed by the equation

$$
\Delta \mathrm{VI}_{\mathrm{I}}=\Delta \mathrm{V}_{\mathrm{oe}} \mathrm{e}^{-\left(\mathbf{P o}_{2} / \mathbf{k}\right)}
$$

where $\Delta \hat{\mathrm{V}}_{0}$ is the ventilation intercept at $\mathrm{PO}_{0_{2}}=\mathrm{O}$ and $k$ is the decrement in $\mathrm{Po}_{2}$ required to increase ventilation by a factor of $\mathrm{e}(2.718)$. Thus a small value for $k$ indicates a large hypoxic ventilatory drive. Constants for the equation were determined by the linear regression of $\ln (\nabla I$ $-0.85 \mathrm{~V}_{100}$ ) on $\mathrm{Po}_{3}$. At least 12 points were used in each regression analysis. These data were tested for fit of an exponential distribution with the Komolgorov-Smirnov test for the distribution of points around a curve (15). This test indicated that the actual data points correlated significantly with the distribution described by the calculated regression line.
TABLE I

Results of Pulmonary Function Testing in the Old Normal Men

\begin{tabular}{|c|c|c|c|c|c|}
\hline Subject & $\begin{array}{c}\text { Vital } \\
\text { capacity }\end{array}$ & $\begin{array}{l}\text { Total } \\
\text { iung } \\
\text { capacity* }\end{array}$ & $\mathrm{FEV}_{1.0 \mathrm{~s}}$ & $\begin{array}{c}\text { FEV } 1.08 / \\
\text { FVC }\end{array}$ & DLcoSB \\
\hline & $m l$ & $m l$ & $m l$ & $\%$ & $\begin{array}{c}m l / m i n \\
\times m m H^{-1}\end{array}$ \\
\hline H. C. & $\begin{array}{l}4,549 \\
(110) \ddagger\end{array}$ & $\begin{array}{r}7,520 \\
(110)\end{array}$ & $\begin{array}{c}3,000 \\
(100)\end{array}$ & 69 & $\begin{array}{c}24 \\
(104)\end{array}$ \\
\hline A. N. & $\begin{array}{c}4,149 \\
(98)\end{array}$ & $\begin{array}{c}6,786 \\
(103)\end{array}$ & $\begin{array}{c}3,275 \\
(101)\end{array}$ & 75 & $\begin{array}{c}24 \\
(111)\end{array}$ \\
\hline L. C. & $\begin{array}{r}3,918 \\
(97)\end{array}$ & $\begin{array}{c}6,334 \\
(100)\end{array}$ & $\begin{array}{r}2,800 \\
(97)\end{array}$ & 75 & $\begin{array}{c}19 \\
(97)\end{array}$ \\
\hline W. $\mathbf{K}$. & $\begin{array}{r}3,651 \\
(91)\end{array}$ & $\begin{array}{r}5,831 \\
(92)\end{array}$ & $\begin{array}{r}2,175 \\
(75)\end{array}$ & 68 & $\begin{array}{c}17 \\
(75)\end{array}$ \\
\hline E. M. & $\begin{array}{r}3,652 \\
(84)\end{array}$ & $\begin{array}{r}6,123 \\
(77)\end{array}$ & $\begin{array}{r}2,150 \\
(67)\end{array}$ & 71 & $\begin{array}{c}17 \\
(62)\end{array}$ \\
\hline L. M. C. & $\begin{array}{r}4,867 \\
(114)\end{array}$ & $\begin{array}{r}7,540 \\
(113)\end{array}$ & $\begin{array}{r}2,825 \\
(92)\end{array}$ & 66 & $\begin{array}{c}28 \\
(135)\end{array}$ \\
\hline J. H. & $\begin{array}{r}4,619 \\
(111)\end{array}$ & $\begin{array}{l}7,952 \\
(121)\end{array}$ & $\begin{array}{l}2,750 \\
(93)\end{array}$ & 57 & $\begin{array}{c}20 \\
(97)\end{array}$ \\
\hline W. L. & $\begin{array}{r}2,400 \\
(65)\end{array}$ & $\begin{array}{r}4,320 \\
(73)\end{array}$ & $\begin{array}{r}1,950 \\
(74)\end{array}$ & 83 & $\begin{array}{l}19 \\
(97)\end{array}$ \\
\hline Mean & 3,976 & 6,551 & 2,616 & 71 & 21 \\
\hline \pm SEM & 276 & 415 & 165 & 3 & 1.4 \\
\hline
\end{tabular}

$\mathrm{FEV}_{1.03}$, forced expiratory volume in $1.0 \mathrm{~s}$; FVC, forced vital capacity; DLcoSB, single breath carbon monoxide diffusing capacity.

* Total lung capacity was calculated from functional residual capacity measured by open circuit $\mathrm{N}_{2}$ washout.

‡ Numbers in parenthesis indicate percent of predicted value obtained from references 7-9.

Heart rate in the hypoxic response test was measured by comparing actual rates and percentage change between control heart rates at $\mathrm{Po}_{2}=100 \mathrm{~mm} \mathrm{Hg}$ and heart rates at $\mathrm{Po}_{2}=40 \mathrm{~mm} \mathrm{Hg}$.

$C O \&$ response. The ventilatory response to hypercapnia was determined by the rebreathing method described by Read (16). A 6 liter bag in a bottle was arranged so that the subject could rebreathe from the main circuit or back in forth into the bag. The rebreathing bag was prefilled with $5 \% \mathrm{CO}_{2}$ in $\mathrm{O}_{2}$. Each subject rebreathed from the bag for $4 \mathrm{~min}$ or until $\mathrm{PACO}_{2}=65 \mathrm{~mm} \mathrm{Hg}$. Two rebreathing tests were done with an intervening rest period. $\mathrm{PAO}_{2}$ remained over $200 \mathrm{~mm} \mathrm{Hg}$ throughout the rebreathing period.

Ventilation in the hypercapnic response test was measured by averaging inspiratory volume over 30 -s intervals after discarding the first $30 \mathrm{~s}$ of the test. Thus approximately 14 points were obtained for analysis on each subject. The relationship relating ventilation to $\mathrm{PcO}_{2}$ is $\mathrm{VI}_{\mathrm{I}}=S\left(\mathrm{PAco}_{2}-B\right)$ where $B$ is the extrapolated $\mathrm{PAco}_{2}$ at $\nabla_{\mathrm{I}}=\mathrm{O}$ (intercept on the abscissa or $\mathrm{PAco}_{2}$ axis) and $S$ is the slope of the $\mathrm{CO}_{2}$ response line (liter $/ \mathrm{min} \times \mathrm{mm} \mathrm{Hg}^{-1}$ ) (17). Constants for this equation were obtained by the linear regression of VI on PAco.

Analysis of the heart rate response to hypercapnia was identical to that done for hypoxia. Percentage change and actual rate differences were calculated between control heart rates immediately after the start of rebreathing and heart rates at $\mathrm{P}_{\mathrm{Aco}}=55 \mathrm{~mm} \mathrm{Hg}$.

Group comparisons for all of the data were made with an unpaired $t$ test. 
TABLE II

Ventilatory Response to Hypoxia and Hypercapnia in Young and Old Normal Subjects

\begin{tabular}{|c|c|c|c|c|c|c|c|c|c|}
\hline \multirow[b]{2}{*}{ Subjects } & \multirow[b]{2}{*}{ Age } & \multirow[b]{2}{*}{$\mathrm{Ht}$} & \multirow[b]{2}{*}{ Wt } & \multicolumn{3}{|c|}{ Response to hypoxia } & \multicolumn{3}{|c|}{ Response to hypercapnia } \\
\hline & & & & $\mathrm{PACO}_{2}$ & $\Delta \dot{V}_{40}$ & $\Delta \dot{\mathrm{V}}_{100}$ & $k$ & $s$ & $B$ \\
\hline & $y r$ & $\mathrm{~cm}$ & $\mathrm{~kg}$ & $m m \mathrm{Hg}$ & liter/min & liter $/ \min$ & $m m \mathrm{Hg}$ & $\begin{array}{c}\text { liter } / \min \\
\times m m \mathrm{Hg}^{-1}\end{array}$ & $m m \mathrm{Hg}$ \\
\hline \multicolumn{10}{|c|}{ Young normals } \\
\hline 1 & 22 & 190 & 63.5 & 42 & 35.0 & 3.8 & 27.1 & 4.2 & 48.6 \\
\hline 2 & 26 & 178 & 77.0 & 37 & 45.4 & 2.0 & 19.2 & 3.1 & 45.7 \\
\hline 3 & 30 & 188 & 85.0 & 43 & 45.2 & 0.8 & 15.2 & 2.5 & 41.0 \\
\hline 4 & 26 & 170 & 65.5 & 40 & 26.4 & 0.7 & 17.1 & 2.5 & 44.8 \\
\hline 5 & 25 & 173 & 64.5 & 40 & 35.1 & 8.5 & 29.6 & 2.1 & 37.5 \\
\hline 6 & 23 & 186 & 79.0 & 45 & 23.0 & 3.9 & 34.0 & 3.3 & 42.0 \\
\hline 7 & 25 & 173 & 59.0 & 40 & 45.7 & 7.5 & 33.2 & 2.9 & 42.7 \\
\hline 8 & 28 & 176 & 65.5 & 40 & 65.3 & 3.4 & 20.5 & 6.3 & 41.9 \\
\hline Mean & 25.6 & 179.3 & 69.9 & 40.9 & 40.1 & 3.8 & 24.5 & 3.4 & 43.0 \\
\hline SEM & 0.9 & 2.7 & 3.2 & 0.9 & 4.7 & 1.0 & 2.6 & 0.5 & 1.2 \\
\hline \multicolumn{10}{|l|}{ Old normals } \\
\hline H. C. & 73 & 182 & 84.5 & 41 & 7.3 & 3.2 & 72.7 & 1.6 & 44.7 \\
\hline A. $\mathrm{N}$. & 68 & 178 & 73.8 & 40 & 14.2 & 2.7 & 36.3 & 1.5 & 43.4 \\
\hline L. C. & 70 & 175 & 91.0 & 42 & 7.8 & 2.6 & 53.5 & 1.2 & 39.0 \\
\hline W. K. & 70 & 175 & 85.0 & 37 & 7.3 & 2.6 & 57.4 & 3.1 & 46.2 \\
\hline E. M. & 64 & 179 & 92.0 & 41 & 9.6 & 2.0 & 32.3 & 2.6 & 45.5 \\
\hline L. M. C. & 69 & 179 & 84.0 & 37 & 16.7 & 2.3 & 30.7 & 2.5 & 42.4 \\
\hline J. H. & 71 & 178 & 72.6 & 39 & 10.3 & 3.4 & 52.5 & 1.9 & 46.0 \\
\hline W. L. & 72 & 170 & 78.0 & 38 & 8.5 & 3.3 & 62.5 & 1.9 & 43.2 \\
\hline Mean & 69.6 & 176.9 & 82.6 & 39.4 & 10.2 & 2.8 & 49.7 & 2.0 & 43.8 \\
\hline SEM & 1.0 & 1.2 & 2.6 & 0.7 & 1.2 & 0.2 & 5.4 & 0.2 & 0.8 \\
\hline$P$ & & & & NS & $<0.001$ & NS & $<0.001$ & $<0.025$ & NS \\
\hline
\end{tabular}

\section{RESULTS}

The ventilatory response to hypoxia at constant $\mathrm{CO}_{2}$ for each of the young and old normal subjects is summarized

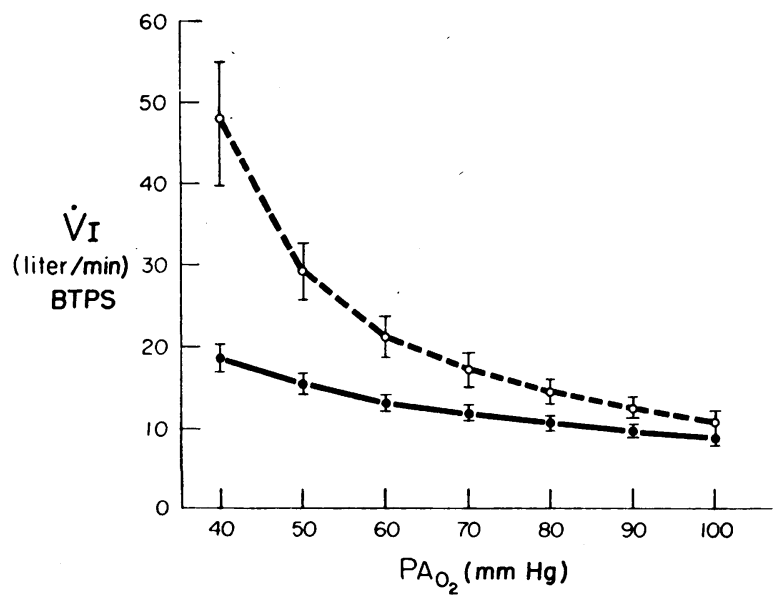

Figure 1 Ventilatory response to isocapnic progressive hypoxia in eight young normal men (broken line) and eight normal men age 64-73 (solid line). Values are means \pm SEM. $\mathrm{PAcO}_{2}=40.9 \pm 0.9$ in the young men and $39.4 \pm 0.7$ in the old men. in Table II. Average response curves for both subject groups are shown in Fig. 1, detailed results of two isocapnic response tests in one of the old men are shown in Fig. 2 , and individual responses are shown in their exponential form in Fig. 3. Although control ventilations $\left(\Delta \vec{V}_{100}\right)$ were more variable in the young normal subjects, there was no significant difference in $\Delta \vec{V}_{100}$ between the two groups. The ventilatory response to hypoxia was strikingly diminished in the old normal subjects. The decrement in $\mathrm{Pos}$ required to increase ventilation by a factor of $\mathrm{e}(2.718$ ), $k$, was $49.7 \pm 5.4 \mathrm{~mm} \mathrm{Hg}$ (mean $\pm S E M$ ) in the old normal subjects and $24.5 \pm 2.6 \mathrm{~mm} \mathrm{Hg}$ in the young normal men. This difference was highly significant $(P<0.001)$. Similarly the incremental ventilation at $\mathrm{PAo}_{2}=40 \mathrm{~mm} \mathrm{Hg}, \Delta \mathrm{V}_{40}$, was $40.1 \pm 4.7$ liters $/ \mathrm{min}$ (mean $\pm \mathrm{SEM}$ ) in the young normal men and 10.2 \pm 1.2 liters/min in the old normal men, also a highly significant difference $(P<0.001)$. The slopes of the individual response lines relating in $\Delta \overline{V I}_{\mathbf{I}}$ to $\mathrm{PAO}_{2}$ in the old normal subjects are not as steep as those of the young normals (Fig. 3). In addition, $\Delta \mathrm{VI}_{\mathrm{I}}$ at $\mathrm{PAO}_{2}=40$ is uniformly smaller in the old normal group without any overlap between groups. 

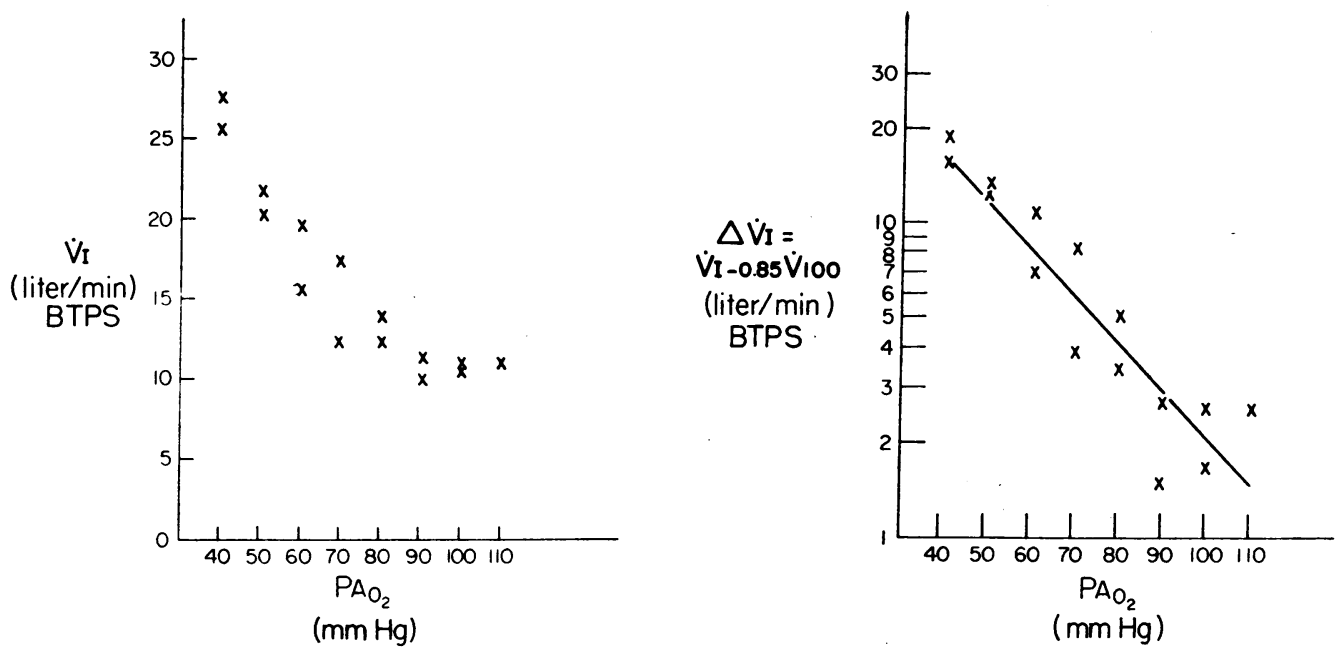

FIGURE 2 Ventilatory response to progressive hypoxia in subject L. M. C. showing analysis of ventilation as an exponential function of $\mathrm{Po}_{2}$. Individual data points from two separate tests are plotted in the left-hand panel and replotted on a semilog scale after subtracting $0.85 \times$ ventilation at $\mathrm{PA}_{\mathrm{O}_{2}}=100 \mathrm{~mm} \mathrm{Hg}$ in the right hand panel. The solid line was calculated by linear regression analysis. $\mathrm{PAcO}_{2}$ was constant at $37 \mathrm{~mm} \mathrm{Hg}$.

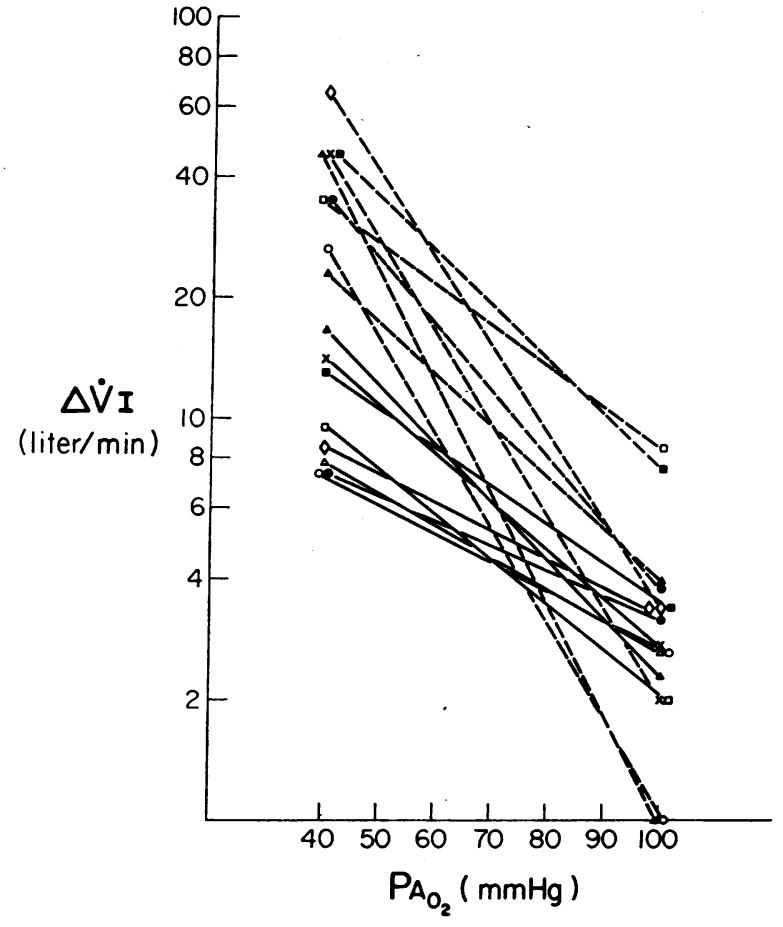

FIGURE 3 Ventilatory response to progressive hypoxia in each of the young (broken lines) and old (solid lines) normal men. $\mathrm{PAcO}_{2}$ is constant at each subject's resting level. $\Delta \nabla_{I}=\nabla_{I}-0.85 V_{100}$. Individual subjects are represented by the following symbols: 1 and $H$. C., $\bullet ; 2$ and A. N., $X$; 3 and L. C., $\triangle ; 4$ and W. K., O; 5 and E. M., $\square ; 6$ and L. M. C., $\Delta ; 7$ and J. H., $\boldsymbol{\square} ; 8$ and W. L., $\diamond$.
The ventilatory response to hypercapnia in each subject is shown in Table II and Fig. 4. There was no difference in the $\mathrm{PAco}_{2}$ at $\mathrm{V}_{\mathrm{I}}=0$ liter/min, $B$, in the two groups. The slope of the response lines relating $V_{I}$ to $\mathrm{PAco}_{2}$ was 3.4 \pm 0.5 liters $/ \mathrm{min} \times \mathrm{mm} \mathrm{Hg}^{-1}$ (mean $\pm S E M$ ) in the young normal subjects and $2.0 \pm 0.2$ liters $/ \mathrm{min} X$ $\mathrm{mm} \mathrm{Hg}{ }^{-1}$ in the old normal men. This difference was significant $(P<0.025)$ but not as great as the difference between the two groups in hypoxic ventilatory drive. This is further illustrated in Fig. 4 where some overlap in the $\mathrm{CO}_{2}$ response lines can be seen between the young and old normal subjects.

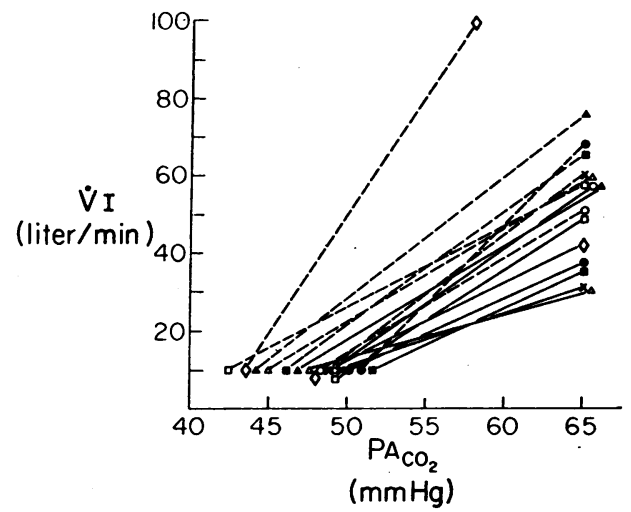

Figure 4 Ventilatory response to rebreathing $\mathrm{CO}_{2}\left(\mathrm{PA}_{\mathrm{O}_{2}}\right.$ $>200 \mathrm{~mm} \mathrm{Hg}$ ) in each of the young (broken lines) and old (solid lines) normal subjects. Symbols for individual subjects are the same as in Fig. 1. 
TABLE III

Heart Rate Response to Hypoxia and Hypercapnia in Young and Old Normal Subjects

\begin{tabular}{|c|c|c|c|c|c|c|}
\hline \multirow[b]{2}{*}{ Subjects } & \multicolumn{3}{|c|}{ Response to hypoxia } & \multicolumn{3}{|c|}{ Response to hypercapnia } \\
\hline & Control & $\begin{aligned} & \mathrm{PAO}_{2} \\
= & 40 \mathrm{~mm} \mathrm{Hg}\end{aligned}$ & $\begin{array}{l}\text { Percent } \\
\text { change }\end{array}$ & Control & $\begin{array}{c}P_{A C_{2}} \\
=55 \mathrm{~mm} \mathrm{Hg}\end{array}$ & $\begin{array}{l}\text { Percent } \\
\text { change }\end{array}$ \\
\hline & per min & per min & $\%$ & per min & per min & $\%$ \\
\hline \multicolumn{7}{|l|}{ Young normals } \\
\hline 1 & 105 & 156 & 47 & 79 & 91 & 15 \\
\hline 2 & 101 & 160 & 58 & 84 & 100 & 19 \\
\hline 3 & 97 & 125 & 29 & 90 & 98 & 9 \\
\hline 4 & 92 & 106 & 15 & 90 & 98 & 9 \\
\hline 5 & 83 & 102 & 23 & 100 & 117 & 17 \\
\hline 6 & 99 & 142 & 30 & 66 & 68 & 3 \\
\hline 7 & 92 & 115 & 25 & 96 & 124 & 29 \\
\hline 8 & 103 & 150 & 46 & 84 & 100 & 19 \\
\hline Mean & 96.5 & 132.0 & 34.1 & 86.1 & 99.5 & 15.0 \\
\hline SEM & 2.5 & 8.1 & 5.2 & 3.7 & 5.9 & 2.8 \\
\hline \multicolumn{7}{|l|}{ Old normals } \\
\hline H. C. & 68 & 81 & 16 & 65 & 66 & 2 \\
\hline A. N. & 72 & 84 & 17 & 68 & 66 & -3 \\
\hline L. C. & 66 & 68 & 3 & 63 & 60 & -5 \\
\hline W. K. & 69 & 78 & 13 & 67 & 69 & 3 \\
\hline E. M. & 69 & 81 & 17 & 69 & 69 & 0 \\
\hline L. M. C. & 90 & 104 & 15 & 84 & 84 & 0 \\
\hline J. H. & 91 & 100 & 10 & 71 & 68 & -4 \\
\hline W. L. & 95 & 96 & 1 & 90 & 90 & 0 \\
\hline Mean & 77.5 & 86.5 & 11.5 & 72.1 & 71.5 & -0.9 \\
\hline SEM & 4.3 & 4.4 & 2.2 & 3.4 & 3.6 & 1.0 \\
\hline$P$ & $<0.005$ & $<0.001$ & $<0.005$ & $<0.025$ & $<0.005$ & $<0.001$ \\
\hline
\end{tabular}

The heart rate response to hypoxia and hypercapnia is shown in Table III. In both instances the control heart rates were significantly higher $(P<0.005$ for hypoxia and $<0.025$ for hypercapnia) in the young normal subjects. Hypoxia ( $\mathrm{PAo}_{2}=40 \mathrm{~mm} \mathrm{Hg}$ ) produced a heart rate of $132 \pm 8 / \mathrm{min}$ (mean $\pm \mathrm{SEM}$ ) in the young normal men and $87 \pm 4 / \mathrm{min}$ in the old normal subjects, a highly significant difference $(P<0.001)$. The percentage increase in heart rate due to hypoxia was $34 \pm 5 \%$ in the young normals and $12 \pm 2 \%$ in the old normals $(P<0.001)$. The percentage increase in heart rate between control at the start of the rebreathing test and $\mathrm{PAco}_{2}=55 \mathrm{~mm} \mathrm{Hg}$ was $15 \pm 3 \%$ (mean \pm SEM) in the young normal men. In contrast to this modest increase in the young normals, hypercapnia produced no change in the heart rate of the old normal men. In fact the average response was a decrease of $1 \pm 1 \%$ (mean $\pm \mathrm{SEM}$ ) in the old normal group. The difference between groups both in actual rate and percentage change due to hypercapnia were highly significant $(P<0.005$ for actual rate and $P<0.001$ for percentage change).

\section{DISCUSSION}

The data presented in this study indicate that hypoxic and hypercapnic ventilatory drive diminishes with in- creasing age. Since this observation is new, it is necessary to consider the possibility that it was produced artifactually by the testing methods, data analysis, or subject selection.

The use of progressive hypoxia at constant $\mathrm{PcO}_{2}$ as a technique for determining the ventilatory response to hypoxia was described by Loeschcke and Gertz (18). More recently, Weil et al. used a slightly longer version of this technique than that used in this study in 10 young normal men (11). They calculated an average $\Delta \mathrm{V}_{40}$ in this group of $17.0 \pm 1.5$ (mean $\pm \mathrm{SEM}$ ) liters/min $\times$ $\mathrm{m}^{-2}$ BTPS, a value very similar to the $21.5 \pm 2.7$ liters/ $\min \times \mathrm{m}^{-2}$ in our young normal subjects. (Note the correction for body surface area.) Several methods for analyzing the relationship between ventilation and $\mathrm{Po}_{2}$ are described in the literature. These include the hyperbolic shape parameter of Weil et al. (11) and the $\Delta \vec{V}_{\omega 0}$ index of Severinghaus et al. (13). Calculation of the ventilatory response to hypoxia in our subjects using either of these indices does not alter the difference between the young and old normal groups. The high oxygen rebreathing $\mathrm{CO}_{2}$ response test is a well accepted technique used both in normal subjects (16) and patients (19). The average slope in our young normal men of $3.4 \pm 0.5$ 
(mean \pm SEM) compares closely with that obtained by Read of $2.7 \pm 0.3$ in 21 normal subjects of unspecified age (16). Recently Patrick and Howard found that the slope of the line relating ventilation to tidal volume during hyperoxic rebreathing $\mathrm{CO}_{2}$ response was inversely related to age (20). The slope of the response line relating ventilation to $\mathrm{PAco}_{2}$ was also decreased in their older as compared with their younger subjects, but the difference was not significant. Further comparison between this study and ours is difficult because their older subjects were only $44 \pm 5 \mathrm{yr}$ (mean $\pm \mathrm{SD}$ ). Although no information is available on how transient tests of hypoxic and hypercapnic ventilatory response compare with steady-state methods in older subjects, it appears unlikely that testing methods or analytical techniques can account for the response differences in young and old subject groups. Since arterial blood samples were not obtained in the old normal men, it is not possible to quantitate the exact humoral stimulus to the chemoreceptors in the two subject groups. Mellengaard (21) and Raine and Bishop (22) found that alveolar to arterial oxygen difference increased with age. Since all the subjects were exposed to an alveolar $\mathrm{Po}_{2}$ of $40 \mathrm{~mm} \mathrm{Hg}$, it is likely that the old normal men received a greater humoral stimulus than the young men during the hypoxic response tests and that our data actually underestimates the extent that hypoxic ventilatory drive diminishes with age.

There remains the possibility that other factors unrelated to chemoreceptor function were operating in the old normal subjects. Several alterations in pulmonary mechanics are known to occur with increasing age. Among these changes are loss of elastic recoil and a decrease in vital capacity with an increase in residual volume and no change in total lung capacity (23-25). Brodovsky, MacDonell, and Cherniack (26) and MilicEmili and Tyler (27) have found that mechanical work is a more accurate gauge of the respiratory response to $\mathrm{CO}_{2}$ than ventilation. Although alterations in mechanical lung function may account for some of the diminished ventilatory response to hypoxia and $\mathrm{CO}_{2}$ seen in the old normal men, it seems unlikely that they can entirely explain their marked attenuation in chemoreceptor function. The old normal subject group was carefully screened to be free of detectable heart and lung disease. In addition, the maximum ventilations reached by the old normal subjects are generally considerably less than their expected maximum breathing capacity calculated by multiplying their $\mathrm{FEV}_{1} \times 30$ (28). Thus the conclusion remains that age in some way directly attenuates chemoreceptor function.

Although there are isolated normal individuals with no ventilatory response to hypoxia $(1,6)$, the only conditions previously reported to be associated with attenuation of chemoreceptor function are hypoxia from birth
(29-32), prolonged exposure to hypoxia in adulthood, $(3,33)$ and athletic physical conditioning (4). ByrneQuinn, Weil, Sodal, Filley, and Grover found that hypoxic ventilatory drive was reduced by $65 \%$ and hypercapnic drive by $53 \%$ in 13 athletes studied at rest as compared with non-athlete controls (4). Weil, ByrneQuinn, Sodal, Filley, and Grover found comparable reductions of $57 \%$ for hypoxic drive and $35 \%$ for hypercapnic drive in 10 long-term non-native residents of Leadville, Colo. $(3,100 \mathrm{~m})$ when compared with natives of Denver, Colo. (1,600 m) (3). Hypoxic ventilatory drive was reduced by an average of $51 \%$ and hypercapnic drive by an average of $41 \%$ in the old normal men of this study. The pattern of attenuation of chemoreceptor function is reasonably similar in all three of these situations and suggests the possibility that some of the factors responsible for the loss of hypoxic and hypercapnic ventilatory drive lie within the peripheral chemoreceptors themselves or in the integrating pathways for the peripheral chemoreceptor impulses within the central nervous system. This premise is based on the assumption that the peripheral chemoreceptors account for about half of the hypercapnic drive in man (34), and the findings of Sørensen and Cruz (35) and Lefrancois et al. (36) that high altitude natives have a decreased response to rapid step increases in $\mathrm{CO}_{2}$. Although the precise defect in the pathway of the peripheral chemoreceptor impulses cannot be determined by this or the other studies cited, it is apparent that virtually all of the peripheral chemoreceptor contribution to hypercapnic ventilatory drive is lost while considerable hypoxic ventilatory drive is retained. This implies either a highly selective effect of age on the peripheral chemoreceptors or, more likely, that alterations in peripheral chemoreceptor function may be one of multiple factors responsible for diminished hypoxic and hypercapnic ventilatory drive in our old normal subjects.

Wade et al. found that hypoxia at constant $\mathrm{PAco}_{2}$ increased systolic blood pressure before and decreased it after bilateral carotid body denervation in four patients undergoing bilateral carotid endarterectomy (14). These findings were later confirmed by Lugliani, Whipp, and Wasserman in eight asthmatics with bilateral carotid body resection (37). Lugliani et al. also found that the tachycardia of hypoxia was not affected by carotid body resection. Both Wade et al. (14) and Lugliani, Whipp, Seard, and Wasserman (38) report intact baroreceptor function after chemoreceptor denervation in their subjects. It is possible that the diminished heart rate response to hypoxia in the old normal men indicates a loss of both baroreceptor and chemoreceptor function with age.

The precise mechanism for the attenuation of the ventilatory and heart rate response to hypoxia and hyper- 
capnia with aging cannot be elicited from this study. It is likely that multiple factors such as chemoreceptor function, baroreceptor function, and possibly the sympathetic nervous system may all play a role. Regardless of the mechanism involved, the finding that the ventilatory and heart rate responses to hypoxia and hypercapnia diminish with increasing age is of considerable clinical importance. First, it exposes one more variable that must be considered in the regulation of respiration in patients or normal individuals particularly if they are also exposed to chronic hypoxia. Secondly, it suggests that the process of aging is associated with the loss of this potentially important protective mechanism. Thus, the patient population most often exposed to hypoxic disease states is also least able to respond to this threat. Further, the usual diagnostic clues indicating the onset of hypoxia may be absent. Hypoxia in the elderly patient might not be signaled by either respiratory distress or tachycardia.

\section{ACKNOWLEDGMENTS}

The authors thank Mrs. Elizabeth Dugan for her technical assistance and Doctors Henry L. Taylor and Henry Blackburn for obtaining the elderly normal subjects. This work was supported by grants RO1-HL-13714 and HL0499712 from the National Heart and Lung Institute and a grant from the Minnesota Respiratory Health Association.

\section{REFERENCES}

1. Dripps, R. D., and J. H. Comroe, Jr. 1947. The effect of the inhalation of high and low oxygen concentrations on respiration, pulse rate, ballistocardiogram and arterial oxygen saturation (oximeter) of normal individuals. Am. J. Physiol. 149: 277.

2. Kronenberg, R. S., and J. W. Severinghaus. 1971. Chemical control of ventilation: man. In Handbook of Respiration and Circulation. P. L. Altman and D. S. Dittmer, editors. Federation of American Societies for Experimental Biology. Bethesda, Md. 102.

3. Weil, J. V., E. Byrne-Quinn, I. E. Sodal, G. F. Filley, and R. F. Grover. 1971. Acquired attenuation of chemoreceptor function in chronically hypoxic man at altitude. J. Clin. Invest. 50: 186.

4. Byrne-Quinn, E., J. V. Weil, I. E. Sodal, G. F. Filley, and R. F. Grover. 1971. Ventilatory control in the athlete. J. Appl. Physiol. 30 : 91.

5. Keys, A., H. L. Taylor, H. Blackburn, J. Brozek, J. T. Anderson, and E. Simonsen. 1963. Coronary heart disease among Minnesota business and professional men followed 15 years. Circulation. 28: 381.

6. Kronenberg, R., F. N. Hamilton, R. Gabel, R. Hickey, D. J. C. Read, and J. W. Severinghaus. 1972. Comparison of three methods for quantitating respiratory response to hypoxia in man. Resp. Physiol. 16: 109.

7. Boren, H. G., R. C. Kory, and J. C. Syner. 1966. The Veterans Administration-Army cooperative study of pulmonary function: II. The lung volume and its subdivisions in normal men. Am. J. Med. 41: 96.

8. Kory, R. C., R. Callahan, H. G. Boren, and J. C. Syner. 1961. The Veterans Administration-Army cooperative study of pulmonary function: I. Clinical spirometry in normal men. Am. J. Med. 30: 243.

9. Teculescu, D. B., and D. C. Stanescu. 1970. Lung diffusing capacity. Normal values in male smokers and non-smokers using the breath-holding technique. Scand. J. Resp. Dis. 51 : 137.

10. Severinghaus, J. W., and F. N. Hamilton. 1970. Endtidal gas sampler. J. Appl. Physiol. 28: 244.

11. Weil, J. V., E. Byrne-Quinn, I. E. Sodal, W. O. Friesen, B. Underhill, G. F. Filley, and R. F. Grover. 1970. Hypoxic ventilatory drive in normal man. J. Clin. Invest. $49: 1061$.

12. Byrne-Quinn, E., I. E. Sodal, and J. V. Weil. 1972. Hypoxic and hypercapnic ventilatory drives in children native to high altitude. J. Appl. Physiol. 32: 44.

13. Severinghaus, J. W., C. R. Bainton, and A. Carcelen. 1966. Respiratory insensitivity to hypoxia in chronically hypoxic man. Resp. Physiol. 1 : 308.

14. Wade, J. G., C. P. Larson, Jr., R. F. Hickey, W. K. Ehrenfeld, and J. W. Severinghaus 1970. Effect of carotid endarterectomy on carotid chemoreceptor and baroreceptor function in man. N. Engl. J. Med. 282: 823.

15. Brunk, H. D. 1965. An Introduction to Mathematical Statistics. Blaisdell Publishing Company, Waltham, Mass.

16. Read, D. J. C. 1967. A clinical method for assessing the ventilatory response to carbon dioxide. Aust. Ann. Med. 16: 20 .

17. Cormack, R. S., D. J. C. Cunningham, and J. B. L. Gee. 1957. The effect of carbon dioxide on the respiratory response to want of oxygen in man. Quart. J. Exp. Physiol. 42: 303.

18. Loeschcke, H. H., and K. H. Gertz. 1958. Einfluss des $\mathrm{O}_{2}$-Druckes in der Einatmungsluft auf die Atemtätigkeit des Menschen, gepruft unter Konstanthaltung des alveolaren $\mathrm{CO}_{2}$-Druckes. Pfluegers Arch. gesamte Physiol. 267: 460

19. Clark, T. J. H. 1968. The ventilatory response to $\mathrm{CO}_{2}$ in chronic airways obstruction. Clin. Sci. 34: 559.

20. Patrick, J. M., and A. Howard. 1972. The influence of age, sex, body size and lung size on the control and pattern of breathing during $\mathrm{CO}_{2}$ inhalation in caucasians. Resp. Physiol. 16: 337.

21. Mellengaard, K. 1966. The alveolar-arterial oxygen difference: its size and components in normal man. Acta Physiol. Scand. $67: 10$.

22. Raine, J. M., and J. M. Bishop. 1963. A-a difference in $\mathrm{O}_{2}$ tension and physiological dead space in normal man. J. Appl. Physiol. 18: 284.

23. Turner, J. M., J. Mead, and M. E. Wohl. 1968. Elasticity of human lungs in relation to age. J. Appl. Physiol. 25 : 664.

24. Pierce, J. A., and R. V. Ebert. 1958. The elastic properties of the lungs in the aged. J. Lab. Clin. Med. 51: 63.

25. Permutt, S., and H. B. Martin. 1960. Static pressurevolume characteristics of lungs in normal males. $J$. Appl. Physiol. 15 : 819.

26. Brodovsky, D., J. A. MacDonell, and R. M. Cherniack. 1960. The respiratory response to carbon dioxide in health and emphysema. J. Clin. Invest. 39: 724.

27. Milic-Emili, J., and J. M. Tyler. 1963. Relation between work output of respiratory muscles and end-tidal $\mathrm{CO}_{2}$ tension. J. Appl. Physiol. 18: 497. 
28. Bates, D. V., P. T. Macklem, and R. V. Christie. 1971. Respiratory Function in Disease. W. B. Saunders Co., Philadelphia, $\mathrm{Pa}$.

29. Sørensen, S. C., and J. W. Severinghaus. 1968. Irreversible respiratory insensitivity to acute hypoxia in man born at high altitude. J. Appl. Physiol. 25: 217.

30. Lahiri, S., F. F. Kao, T. Velasquez, C. Martinez, and W. Pezzia. 1969. Irreversible blunted respiratory sensitivity to hypoxia in high altitude natives. Resp. Physiol. 6: 360 .

31. Edelman, N. H., S. Lahiri, L. Braudo, N. S. Cherniack, and A. P. Fishman. 1970. The blunted ventilatory response to hypoxia in cyanotic congenital heart disease. N. Engl. J. Med. $282: 405$.

32. Sørensen, S. C., and J. W. Severinghaus. 1968. Respiratory insensitivity to acute hypoxia persisting after correction of Tetralogy of Fallot. J. Appl. Physiol. 25: 221.

33. Forster, H. V., J. A. Dempsey, M. L. Birnbaum, W. G. Reddan, J. Thoden, R. F. Grover, and J. Rankin. 1971. Effect of chronic exposure to hypoxia on ven- tilatory response to $\mathrm{CO}_{2}$ and hypoxia. J. Appl. Physiol. $31: 586$.

34. Dejours, P. 1962. Chemoreflexes in breathing. Physiol. Rev. $42: 335$.

35. Sørensen, S. C., and J. C. Cruz. 1969. Ventilatory response to a single breath of $\mathrm{CO}_{2}$ in $\mathrm{O}_{2}$ in normal man at sea level and high altitude. J. Appl. Physiol. 27: 186.

36. Lefrancois, R., H. Gautier, P. Pasquis, A. M. Cevaer, M. F. Hellot, and J. Leroy. 1972. Chemoreflex ventilatory response to $\mathrm{CO}_{2}$ in man at low and high altitudes. Resp. Physiol. 14 : 296.

37. Lugliani, R., B. J. Whipp, and K. Wasserman. 1972. A role for the carotid body in cardiovascular control in man. Clin. Res. 20: 385. (Abstr.)

38. Lugliani, R., B. J. Whipp, C. Seard, and K. Wasserman. 1971. Effect of bilateral carotid-body resection on ventilatory control at rest and during exercise in man N. Engl. J. Med. 285: 1105. 